\title{
Farmers'satisfaction with the performance of the Mooi River Irrigation Scheme, KwaZulu-Natal, South Africa
}

\author{
T Gomo', M Mudhara ${ }^{2 *}$ and A Senzanje ${ }^{1}$ \\ 'School of Engineering, University of KwaZulu-Natal, Pietermaritzburg, South Africa \\ ${ }^{2}$ School of Agricultural, Earth and Environmental Sciences, University of KwaZulu-Natal, Pietermaritzburg, South Africa
}

\begin{abstract}
Farmer satisfaction with using an irrigation service can be used as a measure of performance of an irrigation scheme. An investigation was instituted to determine factors that significantly influence the satisfaction status of farmers at the MooiRiver Irrigation Scheme (MRIS) in KwaZulu Natal, South Africa. A multinomial Logit regression model was employed to analyse the response of the farmers. It was established that about $57 \%$ of the farmers are satisfied with using the irrigation service, $30 \%$ are not and $13 \%$ are neutral. The majority of farmers, accounting for $85 \%$, either never went to school or had only primary level schooling and these are mostly women, who own close to $80 \%$ of the plots in the scheme. Statistically significant results show that 6 household-level factors affect the satisfaction of farmers with using an irrigation service, i.e., gender of head of household, level of education attained by the household head, training received in water management, farmers' perception of the fairness of water distribution, the number of days in a week that plotholders receive water, and the participation of farmers in the inspection of irrigation infrastructure on the scheme. This study recommends formulation of policies to train farmers in water management and to support farmer participation in scheme management.
\end{abstract}

Keywords: Farmer satisfaction, technical performance, multinomial Logit regression

\section{INTRODUCTION}

Internationally, irrigation performance has been the subject of research in the agricultural sector for more than 5 decades. However, these studies have had little impact to date, due to lack of collaborative implementation of recommendations on the part of irrigation stakeholders, among them farmers, policy-makers, and donors. Research has been done from the point of view of the various stakeholders, yet the performance of irrigation schemes, especially in the communally-owned or managed smallholder schemes, has remained low (Svendsen et al., 2009).

The performance of smallholder irrigation (SHI) schemes is affected by a complex set of factors. An understanding of these variables can contribute towards enhancing the performance of smallholder irrigation, improving the livelihoods of the rural poor and ensuring sustainability of the schemes. Key performance issues in SHI schemes range from technical, agronomic, economic and social to institutional issues. These can be explored from different stakeholders' perspectives. Several studies on smallholder irrigation performance have been carried out from the farmers' perspective outside South Africa (Naik and Kalro, 2000; Yercan, 2003; Ghosh et al., 2005, Kuscu et al., 2008; Kuscu et al., 2009). In South Africa, the focus has been on economic (Ntsonto, 2005; Yokwe, 2009) and social performance (Van Averbeke and Mohamed, 2006; Cousins, 2009).

Technical performance research studies have focused on water conveyance, delivery and use in the SHI schemes, and

\footnotetext{
To whom all correspondence should be addressed.

Iiix +27 33260 5518; Fax: +27 332606094 ;

e-mail: mudhara@ukzn.ac.za

Received 15 August 2013; accepted in revised form 6 May 2014.
}

implementation of the recommendations has usually ignored the input from farmers (Plusquellec, 2002; Kuscu et al., 2009), probably due to the misplaced belief that they are unable to understand and contribute to technical issues (FAO, 2001). In the wake of new approaches such as Participatory Irrigation Management (PIM) and Irrigation Management Transfer (IMT), farmers can find themselves entrusted with the responsibility to operate and maintain the schemes, but without technical information and proper management skills, the schemes deteriorate quickly, and frequently require rehabilitation only a few years after construction (FAO, 2001).

Farmer perspectives and assessments of irrigation scheme performance are thus critically important. However, several problems, such as subjective judgments and multicollinearity among the factors considered, are commonly encountered when analysing survey data and assessing the performance of SHI schemes from the farmers' point of view (Magingxa et al., 2006).

The objective of this study was to investigate the social and technical factors that significantly affect the performance of smallholder irrigation schemes and also affect farmers' satisfaction with the irrigation service offered. An irrigation service is measured as the level to which an irrigation system and all its components meet the set objectives of the irrigation scheme. In addition, the service specifies the roles of all parties, which include farmers, Water User Associations (WUAs), operators of the tertiary canal, operators of the secondary canals, operators of the main canals, and project authorities, in operating and maintaining all elements of the system (FAO, 2001).

This study uses farmers' levels of satisfaction with both technical and managerial issues within a scheme as indicative of its performance. Data obtained from farmers to assess the factors affecting the farmers' subjective judgements of the performance of schemes was analysed econometrically. 


\section{METHODS}

Various statistical analysis tools are available for partitioning the factors affecting farmers' levels of satisfaction with the performance of their irrigation schemes. Probabilistic models such as the Logit Model (LM), Probit Model (PM) and the Linear Probability Model (LPM) can be used. A careful selection process must, however, be done to choose the best way to incorporate the farmers' views in the studies on performance assessment. Damisa et al. (2008) recommended the use of the Logit Model for the purpose of analysing the farmers' satisfaction status, because it has the following advantages over the other models:

- The computation of the logistic distribution ensures the rate of the probabilities estimated always lies between 0 and 1 .

- The probability does not increase linearly with a unit change in value of the explanatory variables, as it does in Linear Probability Model, and so the problem of heteroskedasticity is eliminated.

- It is easier to compute and interpret than the Probit Model.

- The dichotomous Logit Model has been used in other studies for analysing the farmers' satisfaction status (Damisa et al., 2008; Kuscu et al., 2009).

Logit regression analysis allows for estimation of the probability that an event occurs or not by predicting a binary or multinomial dependent outcome from a set of independent variables. For example, a farmer's satisfaction status with using an irrigation service can take values such as 1, 2 or 3, denoting dissatisfied, neutral and satisfied, respectively, where the status is dependent upon various independent factors pertaining to the farmer. The Logit model can therefore be employed to estimate the satisfaction status of a randomly selected farmer from an irrigation scheme (Damisa et al., 2008, Kuscu et al., 2009). The Logit model to estimate the probabilities of farmer satisfaction status has 3 categories. If the probability of a farmer being satisfied by using the irrigation service, $\operatorname{Pr}(Y=3)$, is taken as the reference group, then Eqs. (1) and (2) are Logit functions relating to categories 'farmer is not satisfied' and 'farmer is neutral' respectively.

$$
\begin{aligned}
& Z_{1}(X)=\ln \left(\frac{\operatorname{Pr}(Y=1 \mid x)}{\operatorname{Pr}(Y=3 \mid x)}\right)=\ln \left(\frac{P_{1}}{P_{3}}\right) \\
& =\beta_{10}+\beta_{11} X_{1}+\beta_{12} X_{2}+\cdots+\beta_{1 k} X_{k}
\end{aligned}
$$

and

$$
\begin{aligned}
& Z_{2}(X)=\ln \left(\frac{\operatorname{Pr}(Y=2 \mid x)}{\operatorname{Pr}(Y=3 \mid x)}\right)=\ln \left(\frac{P_{2}}{P_{3}}\right) \\
& =\beta_{20}+\beta_{21} X_{1}+\beta_{22} X_{2}+\cdots+\beta_{2 k} X_{k}
\end{aligned}
$$

where:

$X_{1} X_{2} \ldots, X_{k}$ denote the set of explanatory factors assumed to have an effect on $Y$

$Y$ is the dependent variable ('satisfied', 'neutral' or 'not satisfied')

$\beta_{10}$ and $\beta_{20}$ represent the intercepts

$\beta_{11}, \ldots, B_{1 k}$ and $\beta_{21}, \ldots, \beta_{2 k}$ represent the slopes of the Logit regression functions

$Z_{1}(X)$ and $Z_{2}(X)$, respectively (Uysal and Atis, 2010).

Following the dichotomous Logit model (Damisa et al., 2008, Kuscu et al., 2009, Uysal and Atis, 2010), where a farmer was considered to be either satisfied $(Y=1)$ or not $(Y=0)$, and considering the 3-category multinomial Logit function as
2 dichotomous logistic functions, the probabilities of the 3 categories can be shown to be:

$$
\begin{aligned}
& p_{3}=\operatorname{Pr}(Y=3 \mid x)=\frac{1}{1+e^{z_{1}}+e^{z_{2}}} \\
& p_{2}=\operatorname{Pr}(Y=2 \mid x)=\frac{e^{z_{2}}}{1+e^{z_{1}}+e^{z_{2}}} \\
& p_{1}=\operatorname{Pr}(Y=1 \mid x)=\frac{e^{z_{1}}}{1+e^{z_{1}}+e^{z_{2}}}
\end{aligned}
$$

with

$$
p_{3}+p_{2}+p_{1}=1
$$

The model parameters are estimated using the Maximum Likelihood Method (Burnham and Anderson, 2003). In irrigation studies, this model has several applications, which include selection of the best irrigation method suitable in an area (Karami, 2006). In this study, the Logit model was used to determine the factors that significantly affect satisfaction of farmers with an irrigation service in an irrigation scheme.

For data collection, a structured questionnaire was administered on 114 farmers from Mooi-River Irrigation Scheme, selected through stratified random sampling during the 2010/11 irrigation season. Seven local enumerators, who spoke the local language at the study site, were trained to administer the questionnaire. Information collected included age, gender, irrigation training, timeliness of water delivery, water distribution among the blocks, management, farming experience, farmer involvement in inspection of irrigation infrastructure and maintenance, among others. The Logit model for this case was specified as follows:

$$
Y=f\left(x_{1}, x_{2}, x_{3}, \ldots \ldots, x_{k}\right)
$$

where:

$Y$ is the dependent variable, in this case satisfaction with irrigation services

$x_{1}, x_{2}, x_{3}, \ldots, x_{k}$ are the independent variables assumed to have an effect on $Y$.

The factors investigated through the questionnaire were analysed using SYSTAT software to determine those that had significant bearing on farmers' satisfaction status (SYSTAT, 2007).

\section{Study site}

The study was conducted in the Mooi-River Irrigation Scheme (MRIS) located in the Msinga Local Municipality along the floodplains of Mooi River in the Midlands region of KwaZuluNatal Province, South Africa. The scheme is over 600 ha in extent and is home to approximately 824 farmers (DAEA, 2010) and is within a $30 \mathrm{~km}$ radius of a bigger SHI scheme, Tugela Ferry Irrigation Scheme (TFIS). KwaZulu-Natal ranks as the third most important province in the country in relation to the proportion of the total number of smallholder irrigation schemes found within it (11\%), after Limpopo (57\%) and Eastern Cape (23\%) (Denison and Manona, 2007). For management and water distribution, administratively the scheme comprises 15 blocks of varying sizes (Fig. 1). Each block has its own local committee responsible for water allocation falling under an overall scheme management committee.

Water is distributed from the main canal through in-field canals to the edges of the plots. From the plot edge, it is the 


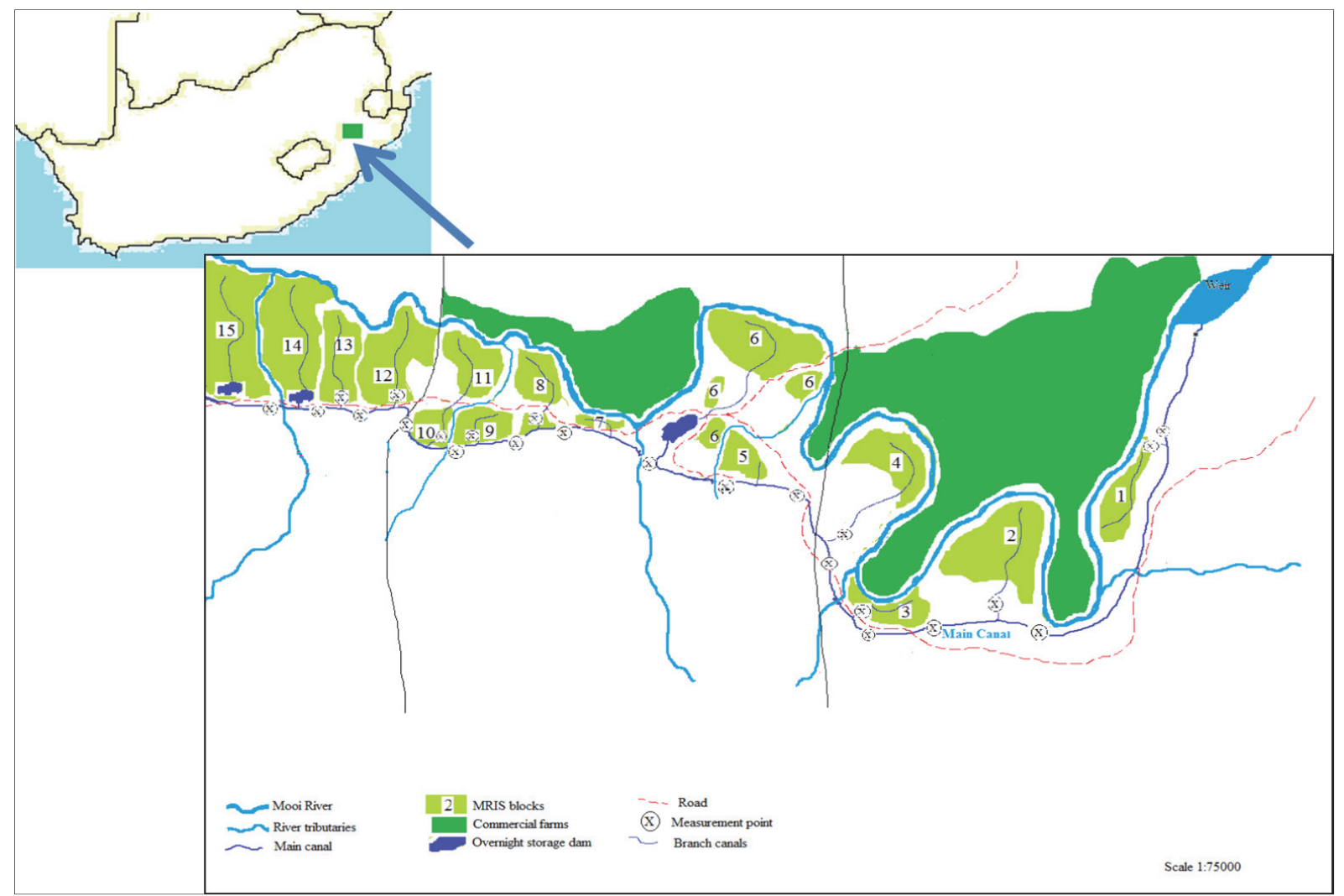

Figure 1

Location of MRIS in South Africa and scheme layout (insert) showing sampling strata (black lines) (DAEA, 2001)

\begin{tabular}{|l|l|l|}
\hline \multicolumn{3}{|c|}{ TABLE 1 } \\
\hline Stratification of the blocks for sampling \\
\hline Head section blocks & Water availability & Blocks \\
\hline Central section blocks & Intermittently available & $5-11$ \\
\hline Tail-end section blocks & Limited water availability & $12-15$ \\
\hline
\end{tabular}

individual farmer's responsibility to irrigate at a specified time for a maximum of $30 \mathrm{~min}$ per plot. Each plot is approximately 0.1 ha in size. In winter the farmers grow mainly horticultural crops for markets in surrounding towns and some residual for home consumption. In summer, maize is grown mainly for own consumption, with a small quantity sold to traders.

\section{Sampling procedure}

The scheme was divided into 3 strata, where each exhibited similar characteristics in relation to water availability and irrigation days. The divisions are shown in Fig. 1 and Table 1.

Each stratum was further sub-divided into 3 zones from which the sample was taken, that is, Upper, Middle, Lower, for farmers whose plots are located closer to the main canal, in the middle and further away, respectively. The sample was reduced to 114 from a possible of 269 using the Raosoft (2010) sample calculator at $95 \%$ level of confidence; see Eqs. (8)-(10).

$$
\begin{aligned}
& v=Z\left({ }^{C} / 100\right)^{2} r(100-r) \\
& n=N v /\left((N-1) E^{2}+v\right)
\end{aligned}
$$

$$
E=\sqrt{\frac{(N-n) v}{n(N-1)}}
$$

where:

$N$ is the population size

$n$ is sample size

$E$ is margin of error

$r$ is the fraction of responses of interest to the researcher $Z(c / 100)$ is the critical value at $95 \%$ confidence level $c$ is the confidence level, $95 \%$ in this study $v$ is the reduced sample size.

A multinomial Logit model was run on Student Version of SYSTAT 12, called MYSTAT (SYSTAT, 2007), with the 15 factors that were assumed to have an effect on the satisfaction status of the farmer. The factors were selected from a pilot survey carried out in the scheme. Each factor hypothesis is summarised in Table 2 and the coding for each category is shown in Table 3. The multicollinearity of the factors was taken into consideration when the data were inputted to the model, by using the software to check the data.

\section{RESULTS}

\section{General characteristics of the scheme}

Results show that $57 \%$ of the farmers are satisfied with using the irrigation service while $30 \%$ are not satisfied and $13 \%$ are neutral, that is, neither satisfied nor dissatisfied. Some $78 \%$ of the plots are owned or used by women. Some $85 \%$ of the farmers had only primary school education while around $15 \%$ had 


\begin{tabular}{|l|l|l|}
\hline \multicolumn{2}{|c|}{ Variables assumed to affect farmer level of satisfaction with using irrigation service and the corresponding hypothesis } \\
\hline Variable & Description & Hypotheses \\
\hline LOC & $\begin{array}{l}\text { Location of the plot in relation to the main } \\
\text { canal }\end{array}$ & Farmers with plots close to the main canal will be satisfied \\
\hline GENDER & Whether the plot is owned by a female or male & Female farmers will be more satisfied with the service \\
\hline AGE & Age of the farmer & Older farmers are more satisfied with the service \\
\hline EDU & Level of education & $\begin{array}{l}\text { Educated farmers are more satisfied with the service owing to } \\
\text { ability to adopt improved innovations }\end{array}$ \\
\hline FARMEXP & $\begin{array}{l}\text { Farming experience of the farmer in the irriga- } \\
\text { tion scheme }\end{array}$ & $\begin{array}{l}\text { Farmers with more farming experience in the scheme are more } \\
\text { satisfied with the service }\end{array}$ \\
\hline RESOWN & Resource ownership by the farmer & Farmers with more resources are more satisfied with the service \\
\hline PLOTS & $\begin{array}{l}\text { Number of plots a farmer cultivates in the } \\
\text { scheme }\end{array}$ & $\begin{array}{l}\text { Farmers with more plots in the scheme are more satisfied with the } \\
\text { service }\end{array}$ \\
\hline TRAINING & $\begin{array}{l}\text { Whether the farmer received training in water } \\
\text { management }\end{array}$ & $\begin{array}{l}\text { Farmers who have been trained in irrigation water management } \\
\text { are more likely to be more satisfied with the service }\end{array}$ \\
\hline WATDEL & $\begin{array}{l}\text { Timeliness of water delivery } \\
\text { Farmers receiving water on time are more inclined to be more } \\
\text { satisfied with the service }\end{array}$ \\
\hline WATDIST & $\begin{array}{l}\text { Satisfaction of farmers with water distribution } \\
\text { among the blocks }\end{array}$ & $\begin{array}{l}\text { Farmers who are satisfied with the distribution will be satisfied } \\
\text { with using the irrigation service }\end{array}$ \\
\hline INSPEC & $\begin{array}{l}\text { Involvement in seasonal inspection of the irri- } \\
\text { gation infrastructure }\end{array}$ & $\begin{array}{l}\text { Farmers involved in seasonal inspection of the irrigation infra- } \\
\text { structure are more satisfied with the service }\end{array}$ \\
\hline OPMAIN & $\begin{array}{l}\text { Involvement in operation and maintenance of } \\
\text { the scheme }\end{array}$ & $\begin{array}{l}\text { Farmers involved in operation and maintenance are more satis- } \\
\text { fied with the service }\end{array}$ \\
\hline
\end{tabular}

\begin{tabular}{|l|l|}
\hline \multicolumn{2}{|c|}{ Variables assumed to affect farmer level of satisfaction with the service in MRIS } \\
\hline Variable & Coding \\
\hline IRRISERV (dependent variable) & $\begin{array}{l}2 \text { if farmer is satisfied with using irrigation service, } 1 \text { if neither satisfied nor dissatisfied, } 0 \text { if not } \\
\text { satisfied }\end{array}$ \\
\hline LOC & $\begin{array}{l}1 \text { if plot is located close to the head of distributary canal, } 2 \text { in the middle, } 3 \text { if close to the tail- } \\
\text { end of the distributary canal }\end{array}$ \\
\hline GENDER & Gender of the farmer: $1=$ Male, 0 = Female \\
\hline AGE & Age of farmer in years \\
\hline EDU & $\begin{array}{l}\text { Level of education of the farmer: EDU=1 if farmer went for Secondary/Tertiary education, } 0 \\
\text { otherwise }\end{array}$ \\
\hline FARMEXP & Number of years the farmer has been irrigating in the scheme \\
\hline RESOWN & $\begin{array}{l}\text { Resource ownership by the farmer: } 2 \text { if farmer owns tractor, } 1 \text { if farmer owns cattle/donkeys, } \\
0 \text { if farmer does not own draft power }\end{array}$ \\
\hline PLOTS & Number of plots the farmer uses within the scheme \\
\hline TRAINING & 1 if farmer has received irrigation training, 0 otherwise \\
\hline WATDEL & Number of days per week the farmer receives water \\
\hline WATDIST & $\begin{array}{l}2 \text { if farmer is satisfied with water distribution among the blocks, } 1 \text { if the farmers is neither } \\
\text { satisfied nor dissatisfied, } 0 \text { if not satisfied with water distribution among the blocks }\end{array}$ \\
\hline INSPEC & 1 if farmer is involved in annual/seasonal inspection of irrigation structures, 0 otherwise \\
\hline OPMAIN & 1 if farmer is involved in operation and maintenance of the scheme, 0 otherwise \\
\hline
\end{tabular}

been to secondary school and beyond. In terms of farming experience, $46.5 \%$ of the farmers had more than 20 years in the scheme while $36 \%$ had between 10 and 20 years of experience; those who had less than 10 years experience constituted the remaining $17.5 \%$. Most of the farmers hire implements such as tractors, cattle or donkeys as sources of draft power, since 65\% do not have their own sources. Only $30 \%$ own animals such as cattle or donkeys that they can use as a source of draft power, while $5 \%$ own tractors. Historically, land was allocated by the Government when the irrigation scheme was established in the early $20^{\text {th }}$ century. Over time the chiefs have been recognised at the custodians of the land and have been approached when farmers want access to unused plots. Households have rights to use the land but cannot sell it. Within households, land ownership is passed from one generation to the next through inheritance. Of the farmers, $7 \%$ own 1 plot in the scheme, while $83 \%$ own between 2 and 9 plots and $10 \%$ own 10 or more plots. It was also established that only $40 \%$ of the farmers have received training in irrigation water management.

Survey results also show that about $74 \%$ of the farmers do not access water at all for a whole week or have access to water for 1 day/week. Those in the central part of the scheme get water for more than 1 day/week but for less than 5 days/week while those in the head of the main canal access water for 6 or 


\begin{tabular}{|c|c|c|c|c|}
\hline \multicolumn{5}{|c|}{$\begin{array}{l}\text { TABLE } 4 \\
\text { Results of multinomial Logit regression analysis of the factors affecting farmer } \\
\text { satisfaction at MRIS }\end{array}$} \\
\hline Parameter & Estimate & Standard error & $\mathrm{Z}$ & $p$-value \\
\hline \multicolumn{5}{|l|}{ Not satisfied } \\
\hline 1 CONSTANT & 1.091 & 1.696 & 0.64 & 0.520 \\
\hline $3 \mathrm{LOC}$ & -0.221 & 0.329 & -0.67 & 0.502 \\
\hline 4 GENDER & $-1.648^{*}$ & 0.890 & -1.84 & 0.065 \\
\hline 5 AGE & 0.004 & 0.028 & 0.13 & 0.895 \\
\hline $6 \mathrm{EDU}$ & -0.456 & 0.924 & 0.49 & 0.621 \\
\hline 7 FARMEXP & 0.022 & 0.023 & 0.95 & 0.344 \\
\hline 8 RESOWN & -0.340 & 0.662 & -0.51 & 0.608 \\
\hline 9 PLOTS & -0.108 & 0.126 & -0.86 & 0.388 \\
\hline 10 TRAINING & $-1.072^{\star}$ & 0.621 & -1.73 & 0.084 \\
\hline 11 WATDEL & -0.215 & 0.260 & -0.83 & 0.409 \\
\hline 13 WATDIST & $-1.295^{\star \star \star}$ & 0.350 & -3.69 & 0.001 \\
\hline 14 INSPEC & 0.769 & 0.641 & 1.20 & 0.230 \\
\hline 15 OPMAIN & 0.607 & 0.670 & 0.91 & 0.364 \\
\hline \multicolumn{5}{|l|}{ Neutral } \\
\hline 1 CONSTANT & 0.955 & 2.639 & 0.36 & 0.717 \\
\hline $3 \mathrm{LOC}$ & -0.649 & 0.473 & -1.37 & 0.170 \\
\hline 4 GENDER & -1.827 & 1.142 & -1.60 & 0.110 \\
\hline $5 \mathrm{AGE}$ & 0.033 & 0.040 & 0.82 & 0.411 \\
\hline $6 \mathrm{EDU}$ & $2.392^{\star}$ & 1.321 & 1.81 & 0.070 \\
\hline 7 FARMEXP & -0.025 & 0.031 & -0.83 & 0.408 \\
\hline 8 RESOWN & 0.138 & 1.035 & 0.13 & 0.894 \\
\hline 9 PLOTS & -0.146 & 0.224 & -0.65 & 0.514 \\
\hline 10 TRAINING & $-2.670^{\star \star}$ & 1.258 & -2.12 & 0.034 \\
\hline 11 WATDEL & $-2.138^{\star}$ & 1.125 & -1.90 & 0.057 \\
\hline 13 WATDIST & -0.242 & 0.492 & -0.49 & 0.622 \\
\hline 14 INSPEC & $2.715^{* *}$ & 1.142 & 2.38 & 0.017 \\
\hline 15 OPMAIN & -0.013 & 0.982 & -0.01 & 0.989 \\
\hline \multicolumn{4}{|l|}{ LR chi2(24) } & $50.91^{\star * \star}$ \\
\hline \multicolumn{4}{|l|}{ Prob $>$ chi $^{2}$} & 0.0011 \\
\hline \multicolumn{4}{|l|}{ Log likelihood } & -64.12 \\
\hline \multicolumn{4}{|l|}{ Pseudo $R^{2}$} & 0.284 \\
\hline
\end{tabular}

${ }^{*}$ significant at $0.1 ;{ }^{* *}$ significant at $0.05 ;{ }^{* * *}$ significant at 0.01

Base outcome is 'satisfied with irrigation service'

7 days/week. Some $75 \%$ of the farmers experience a shortage of water while $25 \%$, mostly in Block 4 and upstream, felt that water supply was adequate. However, despite this water shortage, $49 \%$ of the farmers are satisfied with the water distribution across the blocks, while $39.5 \%$ are not satisfied and the remainder are neither satisfied nor dissatisfied.

Survey data also showed that only $39.5 \%$ of the farmers involved themselves in seasonal inspection of the scheme infrastructure while the rest of the farmers did not take part. Some $34.2 \%$ participated in maintaining the scheme infrastructure. In terms of gender, $71 \%$ were women and $29 \%$ men.

\section{Multinomial Logit analysis}

This section shows the results from the Logit model. The multinomial Logit analysis had 3 levels of the response variable, IRRISERV, where 'farmer is satisfied with taking irrigation service' category was selected as the reference choice group. SYSTAT chooses the level of the dependent variable with the highest frequency as the reference group (SYSTAT, 2007). MYSTAT used the Akaike Information Criterion (AIC) and the Schwarz's Bayesian Information Criterion (BIC) for measuring the goodness of the model, which SYSTAT (2007) describes as more accurate than other methods.

The parameter estimation consists of 2 sets of estimates owing to the fact that the response variable IRRISERV has 3 levels. The first model consists of two IRRISERV categories 0 and 2 , and the second has Categories 1 and 2, as shown in Table 4.

McFadden's rho-squared statistic was used for assessing the model as a whole (SYSTAT, 2007). In this model, it was calculated and found to be 0.257 , which lies in the range 0.20 and 0.40 , described by Hensher and Johnson (1981) as being very satisfactory.

The results also show that location with respect to the water diversion point, location within a block from the main canal, age of the farmer, education level attained by the farmer, farming experience, the number of plots a farmer owns, perceived fairness of water distribution across the blocks and the number 
of days a farmer accesses water are statistically significant in influencing the farmers' satisfaction. The same factors were also shown to influence the satisfaction status of the farmer as opposed to being neutral, except location with respect to water diversion point and number of days a farmer accesses water. The statistical significance of each factor, however, differs depending on the category being considered. The estimate of each factor shows the magnitude of change in the log-odds ratio for any change in the factor but does not explain the change in probability since the probability of satisfaction is a nonlinear function of the Logit (SYSTAT, 2007). The estimate merely reflects the relative importance of the factor.

The other factors do not influence the satisfaction status of the farmers in a statistically significant manner.

\section{DISCUSSION}

\section{Gender}

The variable for gender looked at whether the ownership of a plot by a female or male influenced the level of satisfaction with the irrigation service. The hypothesis was that female farmers will be more satisfied with the irrigation service as they are likely to be more concerned about the achievement of household food availability than cash income, where the latter can result in food security. As a result, the female-headed households are likely to grow a diversity of crops which would not be sensitive to the quality of the irrigation service. Results show that gender had a statistically significant influence on the odds of moving from a position of being satisfied to not being satisfied with the irrigation service. Male-headed households are less likely to be satisfied with the irrigation service by a multiplicative factor of 1.648 compared to female-headed households. The result suggests that males could be more incomeoriented than females who are primarily producing for home consumption. On the other hand, gender did not statistically significantly influence the odds of moving from being satisfied to being neutral. It can be assumed that farmers who are satisfied with the irrigation service endeavour to achieve optimum management, at the level of resources they have, compared to their counterparts. On this basis, female-headed households are more likely to attempt to use their irrigation plots effectively compared to the male-headed ones.

\section{Education level of the farmers}

Education allows farmers to understand the intricacies of irrigation farming. Therefore, farmers who have attained higher education levels are less likely to be satisfied with the irrigation service as they are more enlightened about the conditions that should prevail to achieve good farming. The coefficient for the variable for number of years of education attained by the head of household was statistically significant $(p<0.1)$ for the change in satisfaction from 'satisfied' to 'neutral'. The log odds of moving from a state of 'satisfaction' to that of being 'neutral' increases by a multiplicative factor of 2.392 for each unit increase in the number of years of education that farmers attained. This is probably because better educated farmers understand the potential of the scheme and the factors that influence its performance, have a better understanding of the operations and become neutral as the level of education increases. While the more educated farmers have a better understanding of the irrigation business and aim higher, they also know the effects of the conditions prevailing in the scheme, such as vandalism to canals, which result in poor performance of the scheme. The innovativeness of the more educated farmers is undermined by challenges at the scheme level, such as difficulties in accessing water.

\section{Training in water management}

This variable considered whether receiving training in water management makes farmers more inclined to be satisfied with the irrigation service at MRIS. They are more likely to be satisfied with the irrigation service as they are conversant with the technical possibilities of an irrigation scheme in a smallholder setting. The coefficients for training were statistically significant both for the log odds of moving from 'satisfied' to 'not satisfied' and also for moving from 'satisfied' to 'neutral'. Moving from a household whose head did not get training to one where the head was trained reduces the odds of becoming neutral toward the irrigation service by 2.670 . Similarly, the same shift in household status decreases the odds of not being satisfied with the irrigation service by 1.072 . These results suggest that training is key to ensuring the best management of the irrigation scheme. Trained farmers are more likely to be aware of the potential benefits of irrigation and therefore are better able to assess the discrepancies in the performance of the scheme than untrained farmers. This makes the farmers more amenable to participatory management of the irrigation schemes, which Government is pursuing.

\section{Fairness in water distribution}

The inclusion of a variable for farmers' satisfaction with water distribution among the blocks was based on the hypothesis that farmers satisfied with the distribution will also be satisfied with using the irrigation service. The coefficient estimate for satisfaction with water distribution was statistically significant $(p<0.01)$. The log odds of moving from being 'satisfied' with the irrigation service to being 'not satisfied' decreases when the farmer is satisfied with the water distribution. The log odds of being satisfied with the irrigation service decrease by a multiplicative factor of 1.295. This might be because farmers are aware that some blocks receive more water than others and those who receive the water they require, or at least think that they are getting the correct allocation of water, are more likely to be satisfied with the irrigation service than those who do not. During interviews, farmers also indicated that the management committees are aware of water theft but they do not attend to it; hence, other users get water illegally. This might be a factor contributing to dissatisfaction. It is necessary to maintain transparency regarding the manner in which the scheme functions. This would allow farmers to better understand the challenges that the scheme is facing. Hence, they might endeavour to use the best available water management practices.

\section{Timeliness of water delivery}

Farmers receive water at different times, which are often outside the times prescribed in the general agreement that governs the scheme. The correct times of delivery are missed for a number of reasons, including over-use of water in upstream blocks, which results in limited water availability to downstream blocks. It could therefore be hypothesised that farmers who receive irrigation water on time are more inclined to be more satisfied with the irrigation service than those who do not. The timeliness of water delivery was measured as the number of 
days per week the farmer receives water. The odds of moving from a position of being satisfied with the irrigation service to one of being neutral decreased by a multiplicative factor of 2.138 , with a day increase in the number of days farmers received water per week. This indicates that farmers are more likely to be satisfied than neutral with the irrigation service when the number of days per week they receive water increases. This could be an indication of the limited understanding of irrigation scheduling, which makes farmers want to irrigate their plots as often as they can, regardless of the water saturation levels in their soils. Better education on irrigation scheduling might allow farmers to understand how to apply optimal amounts of water during irrigation.

\section{Inspection of infrastructure}

Farmers' involvement in seasonal inspection of the irrigation infrastructure shows their commitment to ensuring the success of the irrigation and also the availability of a good-quality irrigation service. Farmers involved in seasonal inspection of the irrigation infrastructure are likely satisfied with the outcome of that effort but this involvement could also make them more fully aware of the challenges that the scheme is facing. Participation in inspection of irrigation infrastructure has been shown to have a statistically significant effect in increasing the odds of a famer changing from being 'satisfied' to being 'neutral' about the irrigation service. The log odds of moving from being 'satisfied' to 'neutral' increases by a multiplicative factor of 2.715 for a change from not participating in inspection to being involved. This tendency to being neutral toward participation in inspection of infrastructure probably indicates that farmers take responsibility for the outcome of the quality of the irrigation, and know the full extent of the challenges the scheme faces. This awareness of the constraints the scheme confronts will probably motivate the farmers to continue participating in carrying out inspections and probably also remedial action to address any weaknesses.

\section{CONCLUSIONS}

This study identified 6 farm-level factors that statistically significantly determine farmers' satisfaction with the irrigation service at MRIS. A combination of farmer-level characteristics determines satisfaction with irrigation services. The factors are gender of the head of household, level of education attained by the household head, training received on water management, farmers' perception of the fairness of water distribution, the number of days in a week that plotholders receive water, and the participation of farmers in the inspection of irrigation infrastructure on the scheme.

Satisfaction status was mainly dependent on the fairness of water distribution for irrigation, training received in irrigation water management and participation of farmers in the inspection of irrigation infrastructure. The implications of these findings are that focus should be placed on increasing the participation of female-headed households, and that farmers should be trained in irrigation water management. Improved management of irrigation will make farmers confident with the service and stimulate them to improve the level of agricultural management they use. In addition, as much as possible, farmers should be given incentives to encourage them to participate in monitoring irrigation infrastructure. In part, this can be achieved if Government has a clear policy on irrigation, which elaborates the responsibilities of farmers. Farmers at MRIS were not aware of their responsibilities concerning water management.

It was concluded that farmers at MRIS are aware of the problems bedevilling their scheme but seemed to have no power to resolve them. It is recommended therefore that they play a greater role in decision-making and management of their scheme. There is need to improve management of the irrigation scheme. Block committees need to be strengthened so that they are able to organise training for farmers and to enhance collective monitoring of the condition of irrigation infrastructure.

\section{REFERENCES}

BURNHAM KP and ANDERSON DR (2003) Model Selection and Multi-Model Inference: A Practical Information-Theoretic Approach ( $2^{\text {nd }}$ edn.). Springer, New York.

COUSINS B (2009) Personal communication, 10 December 2009. University of the Western Cape, Cape Town, RSA.

DAEA (DEPARTMENT OF AGRICULTURE AND ENVIRONMENTAL AFFAIRS) (2010) Mooi-River Irrigation Scheme Records, Tugela Ferry Offices. Msinga, KwaZulu-Natal, RSA.

DAMISA MA, ABDULSALAM Z and KEHINDE A (2008) Determinants of Farmers' Satisfaction with their Irrigation System in Nigeria. Trends Agric. Econ. 1 (1) 8-13.

DENISON J and MANONA S (2007) Principles, Approaches and Guidelines for the Participatory Revitalisation of Smallholder Irrigation Schemes Volumes 1 \& 2. WRC Report No. TT 309/07. Water Research Commission, Pretoria.

FAO (2001) Smallholder Irrigation Technology: Prospects for SubSaharan Africa. IPTRID Secretariat Food and Agriculture Organization of the United Nations Paper Number 3 - March 2001. FAO, Rome.

GHOSH S, SINGH R and KUNDU DK (2005) Evaluation of irrigation service utility from the perspective of farmers. Water Res. Manag. $19467-482$.

HENSHER D and JOHNSON LW (1981) Applied Discrete Choice Modelling. Croom Helm, London.

KARAMI E (2006) Appropriateness of farmers' adoption of irrigation methods: The application of the AHP model. Agric. Water Manag. 87 101-119.

KUSCU H, DEMIR AO and KORUKCU A (2008) An assessment of the irrigation management transfer programme: case study in the Mustafakemalpasa irrigation scheme in Turkey. Irrig. Drain. 57 15-22.

KUSCU H, BOLUKTEPE FE and DEMIR AO (2009) Performance assessment for irrigation water Management: A case study in Karacabey Irrigation Scheme in Turkey. Afr. J. Agric. Res. 4 (2) 124-132.

MAGINGXA LL, ALEMU ZG and VAN SCHALKWYK HD (2006) Factors influencing the success potential in smallholder irrigation projects of South Africa: A principal component regression. International Association of Agricultural Economists Conference, 12-18 August 2006, Gold Coast, Australia.

NAIK G and KALRO H (2000) A methodology for assessing the impact of irrigation management transfer from farmer's perspective. Water Polic. 2 445-460.

NTSONTO NE (2005) Economic performance of smallholder schemes: a case study of Zanyokwe, Eastern Cape, RSA. Unpublished MSc Thesis, University of Pretoria.

PLUSQUELLEC H (2002) How design, management and policy affect the performance of irrigation projects: emerging modernization procedures and design standards. FAO Publications. Bangkok, Thailand.

RAOSOFT INCORPORATED (2010) Sample size calculator. URL: http://www.raosoft.com/samplesize.html. (Accessed 10 February 2011).

SVENDSEN M, EWING M and MSANGI S (2009) Measuring Irrigation Performance in Africa. International Food Policy research Institute Discussion Paper 00894. Washington DC, USA. 
SYSTAT (2007) SYSTAT 12: Logistic regression manuals. Chicago, USA. URL: http://www.systat.com. (Accessed 7 March 2011).

UYSAL OK and ATIS E (2010) Assessing the performance of participatory irrigation management over time: A case study from Turkey. Agric. Water Manag. 97 1017-1025.

VAN AVERBEKE W and MOHAMED SS (2006) Smallholder irrigation schemes in South Africa: Past, present and future. Keynote address. 2nd Symposium of the South African National Committee on Irrigation and Drainage, 15-17 November 2006, Aventura Swadini, Mpumalanga. URL: http://www.sancid.org.za/files/keyNotesAdd.doc (Accessed 21 January 2010).

YERCAN M (2003) Management turning-over and participatory management of irrigation schemes: a case of the Gediz river basin in Turkey. Agric. Water Manag. 62 205-214.

YOKWE S (2009) Water productivity in smallholder irrigation schemes in South Africa. Agric. Water Manag. 96 1223-1228. 